\title{
Immunoserologic Pepsin Detection in The Saliva as a Non-Invasive Rapid Diagnostic Test for Laryngopharyngeal Reflux
}

\author{
Emre Ocak, Gözde Kubat, İrfan Yorulmaz
}

Department of Otolaryngology-Head and Neck Surgery, Ankara University Faculty of Medicine, Ankara, Turkey

Background: The most common tool for the diagnosis of laryngopharyngeal reflux (LPR) is still 24-hours esophageal $\mathrm{pH}$ monitoring; there is lack of non-invasive, less expensive and accurate diagnostic tools for this frequent disease.

Aims: To evaluate the accuracy of immunoserologic pepsin detection in the saliva for the diagnosis of LPR.

Study Design: Cross-sectional study.

Methods: A two channeled 24-hour esophageal $\mathrm{pH}$ monitoring catheter was placed in patients with a suspicion of LPR. During the 24-hour period, each patient gave one sample of sputum for the immunoserologic pepsin detection test. Pathologic gastroesophageal reflux (GER) findings, LPR findings, $\mathrm{pH}$ score in the proximal and distal probes when the sputum sample was given were recorded. The sensitivity, specificity, positive and negative predictive values of the pepsin detection test were analyzed and compared to $\mathrm{pH}$ monitoring scores.

Results: The study group consisted of 20 patients who met the criteria. A positive pepsin detection test was elicited from 6 patients. The sensitivity and specificity of the pepsin detection test was $33 \%$ and $100 \%$, respectively. A positive predictive value of $100 \%$ was recorded. When the $\mathrm{pH}$ results of the pepsin positive patients (PPP) and the rest of the study group in the proximal probe at the sample time were compared, the PPP had an apparent acidic $\mathrm{pH}$ value compared to the pepsin negative patients ( $\mathrm{pH}: 3.26$ for the PPP, $\mathrm{pH}: 6.81$ for the pepsin negative patients).

Conclusion: Pepsin detection in the saliva is a recent method and becoming increasingly popular. Because of the benefits and ease of application, a positive salivary pepsin test in a patient suspected of having LPR can be a cost effective, accurate and alternative diagnostic method. Increasing the daily number of sputum samples may increase the sensitivity of the test.

Keywords: Diagnosis, pepsin, reflux, saliva
Gastroesophageal reflux (GER) refers to the backflow of stomach contents into the esophagus, while the term laryngopharyngeal reflux (LPR) means the backflow of stomach contents into the laryngopharynx according to the position statement of the Committee on Speech, Voice, and Swallowing Disorders of the American Academy of OtolaryngologyHead and Neck Surgery (1). Gastroesophageal reflux disease
(GERD) is a term referring to the clinical symptoms, which is caused by advanced GER. GERD is defined as "a condition that develops when the reflux of stomach contents causes troublesome symptoms and/or complications" in the Montreal Classification (2).

Laryngopharyngeal reflux differs from GERD in many ways, such as symptomatology, treatment modalities and

This study was presented as an oral presentation at the $35^{\text {th }}$ National Meeting of Turkish Otolaryngology Head and Neck Surgery, 2-6 November, 2013, Antalya, Turkey. 
TABLE 1. Reflux symptom index

\begin{tabular}{|c|c|c|c|c|c|c|}
\hline \multirow{2}{*}{$\begin{array}{l}\text { Finding within the last month, how did the following problems affect you? } \\
\text { 1. Hoarseness or a problem with your voice }\end{array}$} & \multicolumn{6}{|c|}{$\begin{array}{c}0=\text { No Problem } \\
5=\text { Severe Problem }\end{array}$} \\
\hline & 0 & 1 & 2 & 3 & 4 & 5 \\
\hline 2. Clearing your throat & 0 & 1 & 2 & 3 & 4 & 5 \\
\hline 3. Excess throat mucus or postnasal drip & 0 & 1 & 2 & 3 & 4 & 5 \\
\hline 4. Difficulty swallowing food, liquids or pills & 0 & 1 & 2 & 3 & 4 & 5 \\
\hline 5. Coughing after you ate or after lying down & 0 & 1 & 2 & 3 & 4 & 5 \\
\hline 6. Breathing difficulties or choking episodes & 0 & 1 & 2 & 3 & 4 & 5 \\
\hline 7. Troublesome or annoying cough & 0 & 1 & 2 & 3 & 4 & 5 \\
\hline 8. Sensations of something sticking in your throat or a lump in your throat & 0 & 1 & 2 & 3 & 4 & 5 \\
\hline 9. Heartburn, chest pain, indigestion or stomach acid coming up & 0 & 1 & 2 & 3 & 4 & 5 \\
\hline Total & & & & & & \\
\hline
\end{tabular}

TABLE 2. Reflux finding score

\begin{tabular}{|c|c|}
\hline Findings & Score \\
\hline Subglottic edema & $0=$ Absent, $2=$ Present \\
\hline $\begin{array}{l}\text { Ventricular erythema/ } \\
\text { hyperemia }\end{array}$ & $0=$ None, $2=$ Partial, $3=$ Complete \\
\hline Vocal fold edema & $0=$ None, $2=$ Mild, 3 Severe, $4=$ Obstructive \\
\hline Diffuse laryngeal edema & 0 None, $2=$ Mild, $3=$ Severe, $4=$ Obstructive \\
\hline $\begin{array}{l}\text { Posterior comissure } \\
\text { hypertrophy }\end{array}$ & $0=$ None, $2=$ Mild, $3=$ Severe, $4=$ Obstructive \\
\hline $\begin{array}{l}\text { Granuloma/granulation } \\
\text { of tissue }\end{array}$ & $0=$ Absent, $2=$ Present \\
\hline Thick endolaryngeal mucus & $0=$ Absent, $2=$ Present \\
\hline
\end{tabular}

pathophysiology. Most of the LPR patients do not have heartburn, which is the major symptom of esophagitis $(3,4)$. The incidence of heartburn in patients with LPR is said to be less than $40 \%$ and the incidence of esophagitis is $25 \%$ according to previous studies (5). The primary pathophysiologic mechanism of GERD is the lower esophageal dysfunction, whereas the primary defect in LPR is believed to be upper esophageal dysfunction.

The main elements for the diagnosis of LPR are symptomatology and laryngeal findings. Ambulatory 24-hour double probe $\mathrm{pH}$ monitoring is the most widely used tool for the diagnosis $(6,7)$. However, $\mathrm{pH}$ monitoring has some disadvantages, such as being an invasive, expensive and difficult to apply method. Therefore, more specific, non-invasive and cost effective diagnostic methods are needed for the diagnosis of LPR.

At this point, pepsin, as a potential factor for damage to the mucosal tissues, draws the attention of clinicians. Laryngeal mucosa is resistant to acidic material above $\mathrm{pH} 4$. However, there are some studies showing that the presence of pepsin can damage the laryngeal tissue, even in mild acidic or alkaline environments (8).
Pepsin can be found in many different tissue samples such as laryngeal mucosa, paranasal sinus mucosa, saliva, middle ear effusion, tracheal secretions and bronchoalveolar lavage fluid (9-11). It is a large molecule; therefore, it can be easily detected after gastric reflux. These features make pepsin a good diagnostic marker for LPR.

\section{MATERIAL AND METHODS}

\section{Study design and patient population}

Patients who had at least one LPR symptom, whose reflux symptom index (RSI) was above 15 and reflux finding score (RFS) was above 3 were enrolled in the study (Table 1-2) $(12,13)$. Exclusion criteria were: psychiatric disorders with cooperation disability, previous laryngeal surgery history, any kind of nasal, paranasal, pharyngeal, laryngeal or pulmonary disease which can mimic LPR symptoms and patients who had taken proton pump inhibitors in the last 1 month.

Signed informed consent was obtained from all participants before the study. A double channeled 24-hour esophageal $\mathrm{pH}$ monitoring catheter (MMS USA Inc., Dover, USA) with an interprobe distance of $15 \mathrm{~cm}$ was placed in every patient. The distal probe was placed $5 \mathrm{~cm}$ above the lower esophageal sphincter. During the 24-hour monitoring period, each patient gave one sample of sputum for the pepsin detection test (Peptest, RD Biomed Ltd, Hull, UK) when they had the worst symptoms.

Pathologic GER findings (percentage of time $\mathrm{pH}<4$ in distal probe over 5\%), LPR findings (presence of a single attack of $\mathrm{pH}<4$ in the proximal probe), $\mathrm{pH}$ score in the proximal and distal probes when the sputum sample was given were recorded. The sensitivity, specificity, positive and negative predictive values of the pepsin detection test were analyzed and compared to $\mathrm{pH}$ monitoring scores statistically. Ambulatory $\mathrm{pH}$ monitoring and pepsin detection test analysis were doubleblinded by separate researchers. 


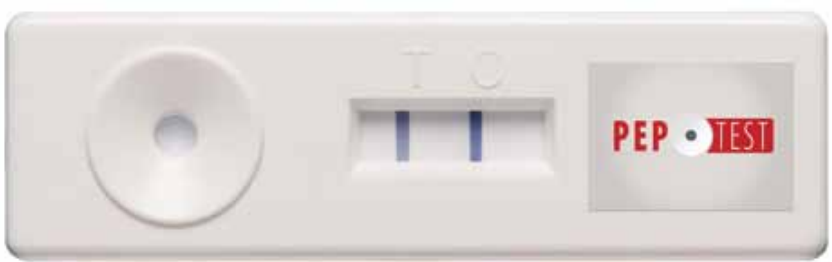

FIG. 1. Pepsin detection kit

The study was performed in accordance with the Declaration of Helsinki, Good Clinical Practice and applicable regulatory requirements. The Ankara University Ethics Committee (EC) approved this study (EC 16-534-12).

\section{Immunoserologic pepsin analysis}

Saliva samples were collected in $30 \mathrm{~mL}$ standard tubes containing citric acid to preserve the action of any pepsin present for each patient. Immunoserologic pepsin analysis was performed by an investigator who was blinded to the clinical data. The collection tube was centrifuged at $4000 \mathrm{rpm}$ for 5 minutes. After centrifugation, an automated micropipette was used to collect $80 \mu \mathrm{L}$ from the supernatant layer of the centrifuged saliva sample. Afterwards, this $80 \mu \mathrm{L}$ sample was transferred to another microtube containing $240 \mu \mathrm{L}$ of migration buffer solution. After mixing the sample with a vortex mixer for 10 seconds, a dual bulb pipette was used to draw up the $80 \mu \mathrm{L}$ of the prepared sample to the pepsin detecting device (RD Biomed Ltd, Hull, UK). The device contains two pepsin monoclonal antibodies to identify the presence of pepsin in the saliva (Figure 1). After placing the sample in the tank, as shown in Figure 1, a blue line appeared in the control panel (letter C) confirming that the test was working correctly. Subsequent to the blue line in the control panel, a second blue line appeared in the test panel (letter T) between 5 and 15 minutes, stating that the sample contained pepsin. The test has the ability to detect pepsin down to $16 \mathrm{ng} / \mathrm{mL}$ (14).

\section{RESULTS}

The study group consisted of 20 patients (range 18-61 years old) who met the criteria. There were 12 female and 8 male patients. The mean RSI was 22.1 and the mean RFS was 8.1. A positive pepsin detection test was elicited from 6 patients. The major symptom at sampling time was heartburn in $35 \%$, coughing in 30\%, sore throat in $25 \%$ and regurgitation in $10 \%$ of the patients. Ninety percent of the patients had at least one LPR attack ( $\mathrm{pH}<4$ in the proximal probe). The mean $\mathrm{pH}$ value was 6.38 in the proximal probe and 4.32 in the distal probe at the sample time. Pathologic GER was recorded in $90 \%$ of the study group (percentage of time $\mathrm{pH}<4$ in distal probe over
TABLE 3. Patients with pathologic gastroesophageal reflux

\begin{tabular}{ccc}
\hline & $\mathrm{pH}<4$ in the distal probe \\
\hline Peptest result & $<5 \%$ & $>5 \%$ \\
Positive & 0 & 6 \\
Negative & 2 & 12 \\
\hline TABLE 4. pH results in the proximal probe at the sample time \\
\hline Peptest result & Mean pH value at the sample time \\
Positive & Distal probe & Proximal probe \\
Negative & 5.38 & 3.26 \\
\hline
\end{tabular}

$5 \%$ ). All of the pepsin positive patients (PPP) were within this pathologic GER group (Table 3).

According to our test results, the sensitivity and specificity of the pepsin detection test for GER was $33 \%$ and $100 \%$, respectively. The positive predictive value was $100 \%$, while the negative predictive value was $14.2 \%$. Among the $\mathrm{PPP}, \mathrm{pH}<4$ in $66 \%$ of the distal probe and $33 \%$ of the proximal probe at the sampling time. When the $\mathrm{pH}$ results of the PPP and the rest of the study group in the proximal probe at the sample time were compared; PPP had an apparent acidic $\mathrm{pH}$ value than the pepsin negative patients (pH: 3.26 for the PPP, $\mathrm{pH}$ : 6.81 for the pepsin negative patients, Table 4).

\section{DISCUSSION}

Laryngopharyngeal reflux is a frequent but mostly misdiagnosed disease in otolaryngology practice. As our knowledge about the pathophysiology of GER and LPR increases, additional patients with nonspecific symptoms will be treated in the correct way. LPR is the underlying factor of many diseases such as pneumonia, rhinosinusitis, asthma, laryngeal cancer and many benign vocal fold lesions (15).

The diagnosis of LPR is challenging because of the atypical symptoms. Currently, 24-hour double probe $\mathrm{pH}$ monitoring is the most common tool for the diagnosis of LPR (16). However, the false negative results obtained via $\mathrm{pH}$ monitoring is within the range of 15 to $30 \%$ (17). $\mathrm{pH}$ monitoring is an invasive and expensive method which may be difficult to use in practice $(18,19)$. Knight et al. (15) reported that approximately $12 \%$ of patients do not tolerate this test. In addition, dietary modifications can lead to false negative $\mathrm{pH}$ study results and non-acidic reflux $(\mathrm{pH} \geq 4)$ cannot be detected by $\mathrm{pH}$ monitoring. Another difficulty of $\mathrm{pH}$ monitoring is locating the probes in the right position. Postma et al. (20) reported that if the proximal probe is situated higher in the hypopharynx, the sensor would not contact the mucosa, which would cause erroneous results. Multichannel intraluminal impedance, a more recent tool, is a sensitive method but also carries most 
of the disadvantages of $\mathrm{pH}$ monitoring. These handicaps create the need for a less invasive, cost effective and sensitive diagnostic test (21).

The gastric enzyme pepsin is a member of the family of aspartic proteins, synthesized by the chief cells of the gastric fundus epithelium (22). Pepsin exhibits maximal activity at pH 2.0 and is inactive at $\mathrm{pH} 6.5$ and above. However, pepsin is not fully denatured or irreversibly inactivated until $\mathrm{pH}$ 8.0 (23). Pepsin plays the major role in the formation of gastroesophageal reflux and related diseases (24). Acidic reflux material can reach into the esophageal, oropharyngeal and tracheal mucosa. Gastric contents include pepsin but not acid in every reflux episode; regarding this, several studies show that acid does not damage the mucosa by itself. These studies state that pepsin plays the key role in mucosal injury, which can explain the mechanism of injury in the laryngeal mucosa in non-acidic reflux (25). Moreover, laryngeal epithelium has been shown to be more sensitive to the damage caused by pepsin than esophageal epithelium.

In a study by Yuksel et al. (14) in vitro bench testing was conducted on 52 gastric juice and 54 sterile water samples to assess test sensitivity and specificity. The pepsin detecting test operating characteristics analysis of in vitro samples found an assay sensitivity and specificity of $87 \%$, a positive predictive value of $85 \%$ and a negative predictive value of $68 \%$. An immunoserologic test was used similar to the latter study. Another study reports a sensitivity of $89 \%$ and a specificity of $68 \%$ in a salivary pepsin western blot analysis (26). Other relevant studies also recommend pepsin as a diagnostic marker $(27,28)$.

In this prospective study, we aimed to investigate the accuracy, usefulness, sensitivity and specificity of immunoserologic pepsin detection in the saliva. In vitro pepsin detection tests were compared to the 24-hour double probe $\mathrm{pH}$ monitoring results for each patient. The high specificity rate in our study suggested that a positive salivary pepsin test in a patient suspected of LPR can be strong evidence for the diagnosis. However the low sensitivity rate indicates uncertainty in the sample collecting frequency. In our study group, patients only collected their sputum once, when they had the worst reflux symptom. This may have caused the low sensitivity value; increasing the number of sputum samples may increase the sensitivity of the test. The sensitivity and negative predictive value is lower when compared to the relevant previously published studies. The lack of a control group and the limited numbers of patients are the limitations of our study. Nonetheless, we believe that our study will help to optimize the sample collecting procedure for further studies.

It is clear that pepsin has a key role in tissue damage in LPR and it has been well established that pepsin can cause mucosal damage, even in non-acidic reflux episodes. Therefore, pepsin can be a good alternative as a diagnostic method, particularly in patients with non-acidic reflux. The evaluation of sputum for pepsin by immunoserology is a rapid, easy to perform and cost effective method. However, optimal frequency of sampling should be further studied in order to increase the diagnostic sensitivity for pepsin detection.

Ethics Committee Approval: Ethics committee approval was received for this study from Ankara University Ethics Committee (EC 16-534-12).

Informed Consent: Written informed consent was obtained from patients who participated in this study.

Peer-review: Externally peer-reviewed.

Author contributions: Concept - I.Y., E.O., G.K.; Design - I.Y.; Supervision - I.Y.; Resource - E.O., G.K.; Materials - E.O., G.K.; Data Collection\&/orProcessing - E.O., G.K.; Analysis\&/orInterpretation - E.O., G.K., I.Y.; LiteratureSearch - E.O., G.K.; Writing - E.O., G.K.; Critical Reviews - E.O., I.Y.

Conflict of Interest: No conflict of interest was declared by the authors.

Financial Disclosure: The authors declared that this study has received no financial support.

\section{REFERENCES}

1. Koufman JA. Laryngopharyngeal reflux is different from classic gastroesophageal reflux disease. Ear Nose Throat $J$ 2002;81(Suppl 2):7-9.

2. Vakil N, van Zanten SV, Kahrilas P, Dent J, Jones R; Global Consensus Group. The Montreal definition and classification of gastroesophageal reflux disease: a global evidence-based consensus. Am J Gastroenterol 2006;101:1900-20. [CrossRef]

3. Koufman J, Sataloff RT, Toohill R. Laryngopharyngeal reflux: consensus conference report. J Voice 1996;10:215-6. [CrossRef]

4. Belafsky PC, Postma GN, Daniel E, Koufman JA. Transnasal esophagoscopy. Otolaryngol Head Neck Surg 2001;125:588-9. [CrossRef]

5. Koufman JA. The otolaryngologic manifestations of gastroesophageal reflux disease (GERD): a clinical investigation of 225 patients using ambulatory 24-hour $\mathrm{pH}$ monitoring and an experimental investigation of the role of acid and pepsin in the development of laryngeal injury. Laryngoscope 1991;101(Suppl 53):1-78.

6. Grøntved ÅM, West F. pH monitoring in patients with benign voice disorders. Acta Otolaryngol Suppl 2000;120:229-31. [CrossRef]

7. Johnson PE, Koufman JA, Nowak LJ, Belafsky PC, Postma GN. Ambulatory 24-Hour Double-Probe $\mathrm{pH}$ Monitoring: The Importance of Manometry. Laryngoscope 2001;111:1970-5. [CrossRef]

8. Bulmer DM, Ali MS, Brownlee IA, Dettmar PW, Pearson JP. Laryngeal mucosa: its susceptibility to damage by acid and pepsin. Laryngoscope 2010;120:777-82. [CrossRef]

9. Sole ML, Conrad J, Bennett M, Middleton A, Hay K, Ash-worth S, Mehta DI. Pepsin and amylase in oral and tracheal secretions: a pilot study. Am J Crit Care 2014;23:334-8. [CrossRef] 
10. Dinis PB, Subtil J. Helicobacter pylori and laryngopharyngeal reflux in chronic rhinosinusitis. Otolaryngol Head Neck Surg 2006;134:67-72. [CrossRef]

11. Krishnan U, Mitchell JD, Messina I, Day AS, Bohane TD. Assay of tracheal pepsin as a marker of reflux aspiration. J Pediatr Gastroenterol Nutr 2002;35:303-8. [CrossRef]

12. Belafsky PC, Postma GN, Koufman JA. Validity and reliability of the reflux symptom index (RSI). J Voice 2002;16:274-7. [CrossRef]

13. Belafsky PC, Postma GN, Koufman JA. The validity and reliability of the reflux finding score (RFS). Laryngoscope 2001;111:1313-7. [CrossRef]

14. Yuksel ES, Hong S-KS, Strugala V, Slaughter JC, Goutte M, Garrett CG, et al. Rapid Salivary Pepsin Test: Blinded Assessment of Test Performance in Gastroesophageal Reflux Disease. Laryngoscope 2012;122:1312-6. [CrossRef]

15. Knight J, Lively MO, Johnston N, Dettmar PW, Koufman JA. Sensitive pepsin immunoassay for detection of laryngopharyngeal reflux. Laryngoscope 2005;115:1473-8. [CrossRef]

16. Bollschweiler E, Feussner H, Hölscher AH, Siewert J. pH monitoring: the gold standard in detection of gastrointestinal reflux disease? Dysphagia 1993;8:118-21. [CrossRef]

17. Tseng D, Rizvi AZ, Fennerty MB, Jobe BA, Diggs BS, Sheppard $\mathrm{BC}$, et al. Forty-eight-hour $\mathrm{pH}$ monitoring increases sensitivity in detecting abnormal esophageal acid exposure. $J$ Gastrointest Surg 2005;9:1043-52. [CrossRef]

18. Jiang A, Liang M, Su Z, Chai L, Lei W, Wang Z, et al. Immunohistochemical detection of pepsin in laryngeal mucosa for diagnosing laryngopharyngeal reflux. Laryngoscope 2011;121:1426-30. [CrossRef]

19. Vaezi MF. Gastroesophageal reflux disease and the larynx. $J$ Clin Gastroenterol 2003;36:198-203. [CrossRef]
20. Postma GN, Belafsky PC, Aviv JE, Koufman JA. Laryngopharyngeal reflux testing. Ear Nose Throat J 2002;81:14-8.

21. Wise JL, Murray JA. Utilising multichannel intraluminal impedance for diagnosing GERD: a review. Dis Esophagus 2007;20:83-8. [CrossRef]

22. Dunn BM. Structure and mechanism of the pepsin-like family of aspartic peptidases. Chem Rev 2002;102:4431-58. [CrossRef]

23. Johnston N, Dettmar PW, Bishwokarma B, Lively MO, Koufman JA. Activity/stability of human pepsin: implications for reflux attributed laryngeal disease. Laryngoscope 2007;117:1036-9. [CrossRef]

24. Samuels TL, Johnston N. Pepsin as a causal agent of inflammation during nonacidic reflux. Otolaryngol Head Neck Surg 2009;141:559-63. [CrossRef]

25. Jiang A, Liang M, Su Z, Chai L, Lei W, Wang Z, et al. Immunohistochemical detection of pepsin in laryngeal mucosa for diagnosing laryngopharyngeal reflux. Laryngoscope 2011;121:1426-30. [CrossRef]

26. Kim TH, Lee KJ, Yeo M, Kim DK, Cho SW. Pepsin detection in the sputum/saliva for the diagnosis of gastroesophageal reflux disease in patients with clinically suspected atypical gastroesophageal reflux disease symptoms. Digestion 2008;77:201-6. [CrossRef]

27. Potluri S, Friedenberg F, Parkman HP, Chang A, MacNeal R, Manus C, et al. Comparison of a salivary/sputum pepsin assay with 24-hour esophageal $\mathrm{pH}$ monitoring for detection of gastric reflux into the proximal esophagus, oropharynx, and lung. Dig Dis Sci 2003;48:1813-7. [CrossRef]

28. Samuels TL, Johnston N. Pepsin as a marker of extraesophageal reflux. Ann Otol Rhinol Laryngol 2010;119:203-8. 